\title{
Serum biomarkers as an alternative to vibration controlled transient elastography in liver fibrosis staging in chronic hepatitis $\mathbf{C}$
}

\author{
P. Debnath ${ }^{1}$, S. Nair', P. Rathi', P. Junare', S. Jain', S. Chandnani', A. Singh ${ }^{2}$, Q. Contractor ${ }^{1}$ \\ (1) Department of Gastroenterology, T.N.M.C \& B.Y.L Nair Charitable Hospital, Mumbai, India ; (2) Department of Medicine, Santosh Medical College, Ghaziabad, India.
}

\begin{abstract}
Background: Assessment of liver disease severity in chronic Hepatitis $\mathrm{C}(\mathrm{CHC})$ is essential both in pre-treatment and posttreatment period. We assessed the impact of direct-acting antiviral therapy on liver stiffness regression measured by Vibration Controlled Transient Elastography (VCTE) in patients with CHC and evaluated the diagnostic performance of the APRI and FIB4 scores compared to VCTE in detecting advanced fibrosis and cirrhosis (F3/F4).

Methodology: Retrospective analysis of consecutive patients with CHC who underwent VCTE before and after DAA therapy was done. APRI and FIB-4 scores were compared to VCTE.

Results : 88 (56.78\%) patients-12 (F3) and 76 (F4) according to VCTE, had advanced fibrosis pre-treatment, which reduced to $69(44.52 \%)-10(F 3)$ and 59 (F4) after 12 weeks DAA therapy. Significant reduction in VCTE value from $14.08 \pm 9.05 \mathrm{KPa}$ to $11.84 \pm 8.31 \mathrm{KPa}(\mathrm{p}=\mathbf{0 . 0 0 2})$ was noted. There is significant reduction in APRI, FIB-4 and GUCI score post-treatment which was not the case with Lok score and Bonacini score. Before therapy, FIB-4 outperformed others to predict advanced fibrosis with score $>\mathbf{2 . 1 3}$ (AUC 0.93), having sensitivity $76 \%$, specificity $96 \%$ and accuracy $86 \%$. However post-treatment, APRI and GUCI score performed best to predict F3/F4 fibrosis with score $>0.63$ (AUC 0.97) and $>0.64$ (AUC 0.96), having sensitivity, specificity and accuracy of $85 \%$, $96.6 \%$ and $92 \% ; 85 \%, 96.6 \%$ and $92 \%$ respectively.

Conclusion : Before therapy, FIB-4 had the best accuracy in predicting advanced fibrosis whereas APRI and GUCI score were the best indices post-treatment. (Acta gastroenterol. belg., 2021, 84, 43-50).
\end{abstract}

Keywords : Chronic hepatitis C, APRI, FIB-4, GUCI, lok index, transient elastography.

\section{Background and aims}

Chronic Hepatitis $\mathrm{C}$ (CHC) is one of the most important cause for liver related morbidity including complications like cirrhosis, end-stage liver disease, hepatocellular carcinoma (HCC), ultimately leading to mortality (1). These complications have tripled over the past 15 years, and models project they will peak between 2030 and 2035 (2). Over the past decade therapeutic options for Hepatitis C virus (HCV) infection have evolved from Peg-Interferon plus Ribavirin, to oral Direct Acting Anti-virals (DAA). Peg-interferon and Ribavirin therapy was associated with sub-optimum care and high treatment related toxicity. On the other hand, DAA can achieve Sustained Virological Response (SVR) or cure in maximum patients $(>95 \%)$ with few associated adverse events (3). The advent of oral DAAs has drastically modified the prognosis of patients with $\mathrm{HCV}$ infection. However, the main goal of their use is to increase survival and quality of life by modifying the natural history of the infection (that is, by interrupting the sequence of fibrosis to cirrhosis and HCC) beyond eradication of the virus. The benefits of DAA extends across distinct patient populations, including classical difficult-totreat individuals, such as patients with cirrhosis or liver transplant recipients. Attainment of SVR has been associated with substantial reduction in all-cause as well as liver-related mortality, liver transplantation (LT) and HCC prompting World Health Organisation (WHO) to set targets for elimination of the virus as well as reduction in HCV related complications in future (4-6). The rapid inhibition of $\mathrm{HCV}$ replication seen with DAA seems to be accompanied by initial reductions in liver inflammation that ultimately may result in amelioration and regression of liver fibrosis.

Presence of cirrhosis (METAVIR, F4 or Ishak, 5-6) in $\mathrm{HCV}$ population indicates that patients should be treated for longer duration or different regimen and also, they are to be monitored for portal hypertension related complications and requires HCC screening. So many algorithms have come up using various serum markers and demographic features of patients with or without VCTE. However, given the important clinical implications, in terms of prognosis, monitoring and treatment decisions that follow the diagnosis of cirrhosis, it seems justified to confirm a diagnosis of cirrhosis by two concordant but unrelated tests.

Non-invasive tools for assessment of liver fibrosis has evolved rapidly during the last decade. Various methods are available to reliably measure various stages of liver fibrosis with variable accuracy, which includes imaging techniques and serum biomarkers. As an alternative to liver biopsy, Vibration Controlled Transient Elastography (VCTE) is the most accurate with increasing sensitivity and specificity for advanced stages of fibrosis and has become the mainstay of non-invasive liver fibrosis assessment $(7,8)$. VCTE has also replaced biopsy in some settings (9). Many serum biomarkers

\footnotetext{
Correspondence to : Dr Prasanta Debnath, Room no 717, $7^{\text {th }}$ floor, OPD building, T.N.M.C \& B.Y.L Nair Charitable Hospital, Dr A.L Nair Road, Mumbai Central, Mumbai, Maharashtra, Pin 400008. Phone : +91 8787472958. Fax : 02223027206

E-mail: prasantad89@gmail.com

Submission date : 31/05/2020

Acceptance date : 08/07/2020
} 
are available which are used in combination with good reproducibility and high applicability and many of them can be performed in out-patient clinic with ease. However, two serum fibrosis scores, namely fibrosis 4 (FIB-4) and AST to platelet ratio index (APRI), have been validated for chronic hepatitis $\mathrm{C}$ for staging liver fibrosis (9-11). Moreover, other non-invasive fibrosis indices like Bonacini Cirrhosis Discriminate Score (CDS), Göteborg University Cirrhosis Index (GUCI), Lok index has been studied in chronic HCV population (12-15).

American Gastroenterological Association (AGA) Guidelines recommend VCTE cut-off of $12.5 \mathrm{kPa}$ to detect cirrhosis. Moreover, in non-cirrhotic patients with HCV who have achieved SVR after antiviral therapy, the AGA suggests a post-treatment VCTE cut-off of 9.5 $\mathrm{kPa}$ to rule out advanced liver fibrosis (16). Thus, in such patients we can rule out advanced fibrosis and consider discharging patients from a dedicated liver clinic and further screening for developing complications, HCC surveillance can be avoided.

Hence, we have conducted this study to look for sequential changes in fibrosis parameters in patients with chronic $\mathrm{HCV}$ infection on DAA therapy and in post treatment period. Moreover, we evaluated the efficiency of FIB-4, APRI, CDS, GUCI and Lok Index values in comparison to VCTE, in the assessment of hepatic fibrosis in chronic hepatitis C patients, as VCTE is not available at every center, largely because of technical and practical reasons together with its high cost, while APRI and FIB-4 scores have been proved quite reliable for assessing liver fibrosis.

\section{Methodology}

Patients with $\mathrm{CHC}$ who received a complete course of DAA therapy from January 2016 to July 2019 were enrolled in this retrospective analysis. Ethical clearance has been taken from Institute Ethics Committee.The inclusion criteria were as follows: i. Adults $(>18 \mathrm{y})$ with $\mathrm{HCV}$ with detectable $\mathrm{HCV}$ RNA (detection limit $=15 \mathrm{IU} / \mathrm{mL}$; COBAS TaqMan HCV test) ii. Patients who have completed antiviral therapy with DAAs, iii. Underwent liver stiffness measurement using VCTE before starting therapy, iv. At least one follow-up VCTE and routine investigations performed after 12 weeks of completion of therapy and the exclusion criteria were as follows : i. Presence of liver disease caused by other etiologies, ii. Decompensated liver disease, iii. HCC at baseline, iv. Co-infection with hepatitis $\mathrm{B}$ virus and/or human immunodeficiency virus, v. invalid VCTE-LS assessments and vi. laboratory findings of acute hepatitis (alanine aminotransferase (ALT) levels $\geq 10$ upper limit of normal).

Demographic data, complete blood count analysis results, and biochemical data were collected at baseline, week 4 , end of treatment, and 12 weeks post completion of treatment.

\section{Laboratory tests}

Complete blood count analyses and blood biochemistry tests, were performed in the central laboratory of the hospital. HCV RNA was monitored at baseline, week 4, and 12 weeks post treatment. HCV genotyping was also performed at baseline.

\section{Hepatic stiffness measurement}

Liver stiffness measurements were performed using VCTE (FibroScan, Echosens, Paris, France) done in supine position, with the tip of the transducer placed on the skin between 9th to 11th intercostal space over the right lobe of the liver $(9,17)$. Only the $M$ probe was used for LS measurement. Patients were fasting for a minimum of 6 hours prior to TE. Values for each patient were calculated as median of a minimum of 10 consecutive measurements. To assure quality of measurements, VCTE exams with an interquartile range (IQR) divided by mean value (IQR/M) of $>30 \%$ or a success rate of $<60 \%$ were excluded, as recommended by the manufacturer and current guidelines (9). The proposed schedule for this study was TE measurement at baseline before DAA treatment and 12 weeks after end of DAA treatment. Results were recorded in kilopascal $(\mathrm{kPa})$ ranging from 3 to a maximum value of $75 \mathrm{kPa}$.

While the correlation of VCTE with METAVIR fibrosis stages has been established by several studies, different cutoffs for each stage of fibrosis have been proposed $(18,19)$. In our study, the staging of liver fibrosis was based on the following cut-offs : $<7 \mathrm{kPa}$ for F0-F1, 7.1-9.5 kPa for F2, 9.6-12.5 kPa for F3, and $\geq$ $12.6 \mathrm{kPa}$ for F4 (20).

Table I. - Equations for various scores

\begin{tabular}{|c|c|c|c|}
\hline \multicolumn{4}{|c|}{$\begin{array}{l}\text { Bonacini Cirrhosis Discriminate Score (21) : (CDS, possible total } \\
\text { score 0-11): }\end{array}$} \\
\hline Score & $\begin{array}{l}\text { Platelet score } \\
\quad\left(\times 10^{9} / \mathbf{L}\right)\end{array}$ & $\begin{array}{l}\text { ALT/AST Ratio } \\
\text { score }\end{array}$ & INR score \\
\hline 0 & $>340$ & $>1.7$ & $<1.1$ \\
\hline 1 & $280-340$ & $1.2-1.7$ & $1.1-1.4$ \\
\hline 2 & $220-279$ & $0.6-1.1$ & $>1.4$ \\
\hline 3 & $160-219$ & $<0.6$ & \\
\hline 4 & $100-159$ & & \\
\hline 5 & $40-99$ & & \\
\hline 6 & $<40$ & & \\
\hline \multicolumn{4}{|c|}{$\begin{array}{l}\text { AST/platelet ratio index (APRI) (11): (AST/upper limit of normal } \\
\text { AST }) \times\left(100 / \text { platelet count }\left[\times 10^{3} / \mathrm{mm}^{3}\right]\right)\end{array}$} \\
\hline \multicolumn{4}{|c|}{$\begin{array}{l}\text { FIB-4 score (22): }\left(\text { Age }[\text { years] } \times \text { AST }(\mathrm{IU} / \mathrm{L})) /\left(\text { platelet } \operatorname{count}\left(10^{\%} /\right.\right.\right. \\
\left.\mathrm{L}) \times(\mathrm{ALT}(\mathrm{IU} / \mathrm{L}))^{1 / 2}\right)\end{array}$} \\
\hline \multicolumn{4}{|c|}{$\begin{array}{l}\text { Lok index (14): } \exp (\log \text { odds }) /[1+\exp (\log \text { odds })] \\
\log \text { odds }=-5.56-\left(0.0089 \times \text { platelet count }\left[\times 10^{3} / \mathrm{mm}^{3}\right]\right)+(1.26 \times \\
\text { AST/ALT ratio })+(5.27 \times \text { INR })\end{array}$} \\
\hline \multicolumn{4}{|c|}{$\begin{array}{l}\text { Göteborg University Cirrhosis Index (GUCI) (23): } \\
\text { [AST/Upper Limits of Normal }(\text { ULN)] X (prothrombin-INR } \times 100) \\
\text { Platelet count }\left(\times 10^{\circ} / \mathrm{L}\right)\end{array}$} \\
\hline
\end{tabular}

Abbreviations : ALT: Alanine Transaminase, AST : Aspartate Transaminase. 
The serum based non-invasive biomarkers were calculated by using the following formulas shown in Table I :

\section{Statistics}

Statistical analysis was performed using SPSS 22.0 (IBM Corp, Armonk, NY USA). Continuous variables are represented by their median (IQR) or mean \pm standard deviation. Statistical analysis was performed using the paired $t$-test for comparisons of continuous variables between groups and the corrected Chi-squared test for comparisons of qualitative data. Diagnostic performances for APRI and FIB-4 scores versus TE-LS were analyzed separately, according to sensitivity, specificity, accuracy, and area under the receiver operating characteristic (ROC) curve. A two-tailed P-value $<0.05$ was considered to be statistically significant.

\section{Results}

From January 2016 to July 2019, a total of 188 patients of chronic Hepatitis C including compensated cirrhotics due to $\mathrm{HCV}$ were included. Thirty three of them failed to meet our inclusion criteria- 21 of them had chronic kidney disease with 19 patients on hemodialysis, 5 patients of HIV/HBV co-infection, 2 patients with HCC and follow up data were unavailable for remaining 5 patients. Thus, complete data set was available for 155 patients.

\section{Patient Characteristics}

Amongst all, 151 patients were treatment naïve cases of chronic hepatitis C. Four patients had prior failure to Interferon based therapy. The mean $( \pm \mathrm{SD})$ age of our study population was $43.19 \pm 13.69$ years, with males constituting $82(52.9 \%)$ of all. $91(58.7 \%)$ patients had history of body piercing, 19 (12.25\%) had history of blood transfusion, with history of parenteral drug abuse in $7(4.51 \%)$ and tattooing in $14(9.03 \%)$ patients. Nine $(5.8 \%)$ patients had a first degree family member of chronic hepatitis C. Genotype 3 was the most common genotype causing HCV infection in our study population amounting to $120(77.41 \%)$ followed by Genotype 1 in 27 (17.41\%), Genotype 4 in 4 (2.58\%) and each patient with Genotype 2 and 5. Two patients had non-typable genotype because of low HCV RNA titre. The median HCV RNA count in our patient population was 4,76,792 (2,30,061-18,01,500). The demographic and baseline characteristics of the study population has been tabulated in Table II.

\section{Virological outcomes}

Virological clearance, defined as HCV-RNA $<$ Lower Limit of Quantification with a detection threshold of 15 IU, was observed in $154(99.3 \%)$ patients after 12 weeks of treatment.
Table II. - Demographic and baseline characteristics of the study population

\begin{tabular}{|c|c|}
\hline Characteristics & Value: \\
\hline Age, $($ Mean $\pm S D)$ years & $43.19 \pm 13.69$ \\
\hline $\begin{array}{l}\text { Gender } \\
\text { Male }(\mathrm{N}, \%) \\
\text { Female }(\mathrm{N}, \%)\end{array}$ & $\begin{array}{l}82(52.9 \%) \\
73(47.1 \%)\end{array}$ \\
\hline $\begin{array}{l}\text { Source of Infection, n (\%) } \\
\text { Parenteral drug use } \\
\text { Transfusion } \\
\text { Tattoo } \\
\text { Body piercing } \\
\text { Unknown }\end{array}$ & $\begin{array}{l}7(4.51 \%) \\
19(12.25 \%) \\
14(9.03 \%) \\
91(58.7 \%) \\
44(28.38 \%)\end{array}$ \\
\hline HCV + Family member & $9(5.8 \%)$ \\
\hline Hemoglobin $(\mathrm{g} / \mathrm{dL})$ Mean $\pm \mathrm{SD}$ & $12.58 \pm 2.34$ \\
\hline Platelet $\left(\times 10^{9} / \mathrm{L}\right)($ Mean $\pm \mathrm{SD})$ & $181.64 \pm 72.4$ \\
\hline Bilirubin $(\mathrm{mg} / \mathrm{dL})($ Mean $\pm \mathrm{SD})$ & $0.75 \pm 0.58$ \\
\hline $\mathrm{ALT}, \mathrm{IU} / \mathrm{L}(\mathrm{Mean} \pm \mathrm{SD})$ & $62.09 \pm 41.57$ \\
\hline AST, IU/L (Mean \pm SD) & $58.72 \pm 34.95$ \\
\hline ALP, IU/L (Mean \pm SD) & $178.96 \pm 44.7$ \\
\hline GGT IU/L $($ Mean \pm SD $)$ & $61.91 \pm 33.34$ \\
\hline Albumin $(\mathrm{g} / \mathrm{dL})($ Mean $\pm \mathrm{SD})$ & $3.7 \pm 0.47$ \\
\hline INR $($ Mean \pm SD) & $1.03 \pm 0.11$ \\
\hline Creatinine $(\mathrm{mg} / \mathrm{dL})($ Mean $\pm \mathrm{SD})$ & $0.78 \pm 0.15$ \\
\hline $\begin{array}{l}\text { Quantitative HCV RNA } \\
\text { Median (Interquartile Range) }\end{array}$ & $4,76,792(2,30,061-18,01,500)$ \\
\hline $\begin{array}{l}\text { HCV genotypes, N (\%) } \\
1 \\
2 \\
3 \\
4 \\
5 \\
\text { Non-typable }\end{array}$ & $\begin{array}{l}27(17.41 \%) \\
1(0.64 \%) \\
120(77.41 \%) \\
4(2.58 \%) \\
1(0.64 \%) \\
2(1.29 \%)\end{array}$ \\
\hline
\end{tabular}

Abbreviations : ALP : Alkaline Phosphatase, ALT : Alanine Transaminase, AST : Aspartate Transaminase, GGT : Gamma Glutamyl Transferase, INR : International Normalized Ratio, SD : Standard Deviation.

The number of patients receiving Sofosbuvir combination therapy with Daclatasvir, Ledipasvir or Velpatasvir was 70 (45.2\%), 29 (18.7\%) and 56 (36.1\%) respectively.

\section{Changes in liver stiffness parameters}

In pre-treatment period, the mean $( \pm \mathrm{SD}) \mathrm{VCTE}$ value was $14.08 \pm 9.05 \mathrm{kPa}$, APRI score was $1.42 \pm 1.13$, FIB4 score was $2.88 \pm 3.02$, CDS, GUCI and Lok index of $5.4 \pm 1.94,1.15 \pm 1.12$ and $0.41 \pm 0.24$ respectively. Stages of liver fibrosis according to VCTE were evaluated as F0-1 in $40(25.8 \%), \mathrm{F} 2$ in $27(17.42 \%), \mathrm{F} 3$ in $12(7.75 \%)$ and F4 in $76(49.03 \%)$ patients. Similarly in the post-treatment period the mean $( \pm$ SD) VCTE value was $11.84 \pm 8.31 \mathrm{KPa}$. APRI score, FIB-4 score, CDS, GUCI and Lok index scores in the post-treatment period were $0.54 \pm 0.35,1.91 \pm 1.59,5.7 \pm 1.54,0.6 \pm 0.39$ and $0.52 \pm 0.22$ respectively. The liver fibrosis stages in the post-treatment period were F0-1 in $62(40 \%), \mathrm{F} 2$ in $24(15.48 \%), \mathrm{F} 3$ in $10(6.45 \%)$ and F4 in $59(38.07 \%)$ patients as shown in table III. The decrease in fibrosis stage by 2 stage in post-treatment period i.e. change from F4 to F2 stage was seen in 6 patients whereas change from F3 to F2 stage was seen in 5 patients. 
Table III. - Pre-treatment and post-treatment values of VCTE and other serum based non-invasive markersAPRI, FIB4, GUCI, CDS and Lok Index

\begin{tabular}{|l|c|c|c|}
\hline \multicolumn{1}{|c|}{ Parameters } & Pre-treatment value & Post-treatment value & Pvalue \\
\hline VCTE, KPa & $14.08 \pm 9.05$ & $11.84 \pm 8.31$ & 0.002 \\
\hline \multicolumn{2}{|c|}{ Stages of liver fibrosis according to VCTE, N (\%) } & $62(40 \%)$ \\
\hline F0-1 (<7 kPa) & $40(25.8 \%)$ & $24(15.48 \%)$ & $10(6.45 \%)$ \\
F2 (7.1-9.5 kPa) & $27(17.42 \%)$ & $59(38.07 \%)$ & 0.064 \\
F3 (9.6-12.5 kPa) & $12(7.75 \%)$ & $0.54 \pm 0.35$ & 0.003 \\
F4 ( $\mathbf{1 2 . 6} \mathbf{~ k P a ) ~}$ & $76(49.03 \%)$ & $1.91 \pm 1.59$ & 0.027 \\
\hline APRI score & $1.42 \pm 1.13$ & $5.7 \pm 1.54$ & 0.142 \\
\hline FIB-4 score & $2.88 \pm 3.02$ & $0.6 \pm 0.39$ & 0.041 \\
\hline CDS & $5.4 \pm 1.94$ & $0.52 \pm 0.22$ & 0.24 \\
\hline GUCI & $1.15 \pm 1.12$ & $0.41 \pm 0.24$ & \\
\hline Lok Index &
\end{tabular}

Table IV. - Pre-treatment performance indicators of APRI, FIB-4, CDS, GUCI and Lok Index in F3/F4 patients

\begin{tabular}{|l|c|c|c|c|}
\hline Score & APRI & FIB-4 & CDS & GUCI \\
\hline Fibrosis stage & F3/F4 & F3/F4 & F3/F4 & F3/F4 \\
\hline Cut-off value & 0.855 & 2.13 & 6.5 & 0.78 \\
\hline Sensitivity, \% & 84 & 76 & 60 & 88 \\
\hline Specificity, \% & 80 & 96 & 100 & 80 \\
\hline Accuracy, \% & 82 & 86 & 80 & 80 \\
\hline AUC, \% & 87.36 & 92.96 & 89.12 & 80 \\
\hline
\end{tabular}

Table V. — Post-treatment performance indicators of APRI, FIB-4 CDS, GUCI and Lok Index in F3/F4 patients

\begin{tabular}{|l|c|c|c|c|}
\hline Score & APRI & FIB-4 & CDS & GUCI \\
\hline Fibrosis stage & F3/F4 & F3/F4 & F3/F4 & F3/F4 \\
\hline Cut-off value & 0.63 & 1.64 & 7 & 0.64 \\
\hline Sensitivity, \% & 85 & 85 & 85 & 85 \\
\hline Specificity, \% & 96.66 & 93.33 & 90 & 96.56 \\
\hline Accuracy & 92 & 90 & 88 & 92 \\
\hline AUC & 97 & 96.33 & 90.58 & 73.33 \\
\hline
\end{tabular}

Based on VCTE fibrosis stage classification, we estimated the optimal APRI, FIB-4, CDS, GUCI and Lok index scores, both in pre-treatment and post-treatment period, to predict the presence of advanced fibrosis/ cirrhosis (F3/F4) using ROC curve analysis (Table IV and $\mathrm{V})$.

In pre-treatment period, the optimal APRI score to predict F3/F4 patients as one group indicating advanced fibrosis or cirrhosis was calculated as $>0.855$ (AUC 0.87 ), with sensitivity $84 \%$, specificity $80 \%$ and accuracy $82 \%$ (Fig. 1). Similarly, the optimal FIB-4 score to predict F3/F4 patients as one group was calculated as $>2.13$ (AUC 0.93 ), with sensitivity $76 \%$, specificity $96 \%$ and accuracy $86 \%$ (Fig. 1). For Bonacini CDS optimal score to predict $\mathrm{F} 3 / \mathrm{F} 4$ patients as one group was calculated as 6.5 (AUC 0.89), with sensitivity $60 \%$, specificity $100 \%$ and accuracy $80 \%$ (Fig. 1). In case of GUCI, the optimal score to predict $\mathrm{F} 3 / \mathrm{F} 4$ patients as one group was calculated as 0.78 (AUC 0.87), with sensitivity $88 \%$, specificity $80 \%$ and accuracy $84 \%$ (Fig. 1) and lastly, the optimal Lok index to predict F3/F4 patients as one group was calculated as 0.41 (AUC 0.83 ), with sensitivity $80 \%$, specificity $80 \%$ and accuracy $80 \%$ (Fig. 1).

On the other hand, in post-treatment period, the optimal APRI score to predict F3/F4 patients as one

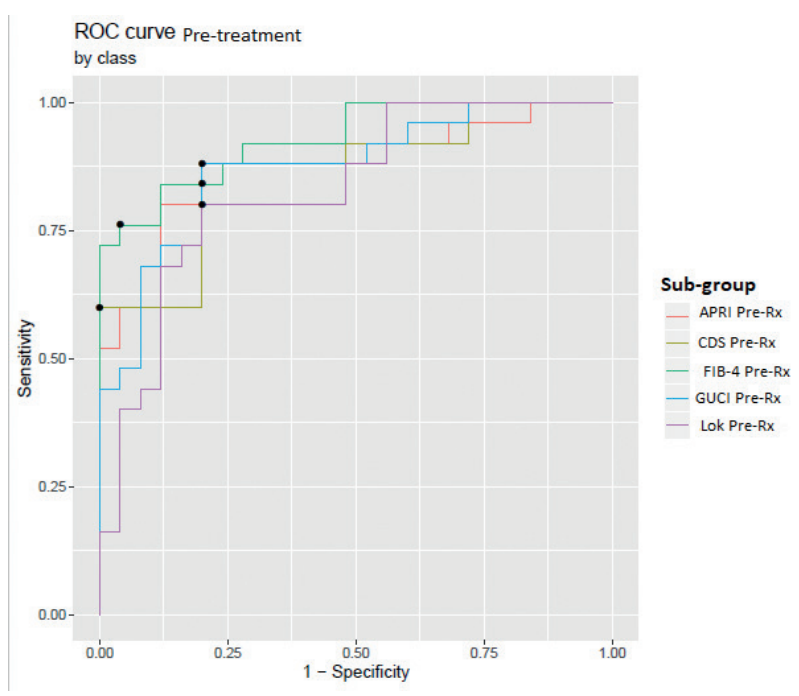

Fig 1. - Performance of APRI, FIB-4, CDS, GUCI and Lok Index in the prediction of advanced fibrosis/cirrhosis (F3/F4) in chronic Hepatitis C according to TE-LS before DAA therapy.

group indicating advanced fibrosis or cirrhosis was calculated as $>0.63$ (AUC 0.97), with sensitivity $85 \%$, specificity $96 \%$ and accuracy $92 \%$ (Fig. 2). Similarly, the optimal FIB-4 score to predict F3/F4 patients as 


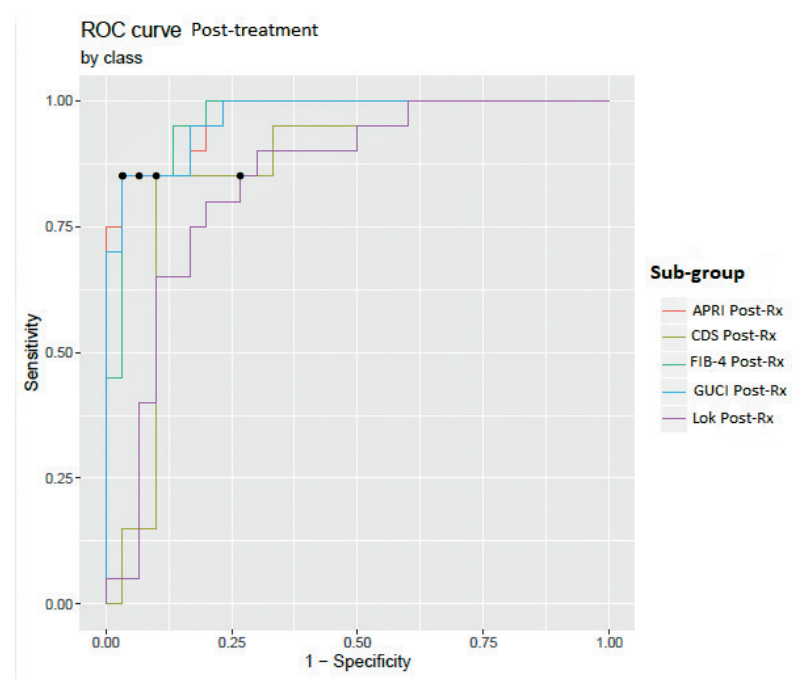

Fig 2. - Performance of APRI, FIB-4, CDS, GUCI and Lok Index in the prediction of advanced fibrosis/cirrhosis (F3/F4) in chronic Hepatitis C according to TE-LS after 12 weeks of DAA therapy.

one group was calculated as $>1.64$ (AUC 0.96), with sensitivity $85 \%$, specificity $93 \%$ and accuracy $90 \%$ (Fig. 2). For Bonacini CDS optimal score to predict F3/F4 patients as one group was calculated as 7 (AUC 0.89), with sensitivity $71 \%$, specificity $94 \%$ and accuracy $84 \%$ (Fig. 2). In case of GUCI, the optimal score to predict F3/F4 patients as one group was calculated as 0.64 (AUC 0.97 ), with sensitivity $85 \%$, specificity $96 \%$ and accuracy 92\% (Fig. 2) and lastly, the optimal Lok index to predict F3/F4 patients as one group was calculated as 0.52 (AUC 0.85 ), with sensitivity $85 \%$, specificity $73 \%$ and accuracy $78 \%$ (Fig. 2).

\section{Discussion}

With worldwide prevalence of approximately 71 million chronically infected individuals, $\mathrm{HCV}$ is a major cause of chronic liver disease (24). Muyldermans et al in their meta-analysis has shown that HCV seroprevalence of $1.01 \%$ in adult general population of Belgium, which constitutes an important health issue (25). The identification of cirrhosis remains a vital step in the pretreatment assessment of patients with chronic hepatitis $\mathrm{C}$ infection, and directly impacts treatment choice, duration, and potential need for Ribavirin, as well as the requirement for variceal and HCC surveillance. However, recent AASLD 2019 guidelines has simplified treatment for $\mathrm{CHC}$ along with compensated cirrhotics (26). Pre-treatment assessment for presence of cirrhosis is mandatory for all patients with non-invasive assessment parameters like- FIB-4, APRI, VCTE and other noninvasive serologic tests like Fibrosure, Enhanced Liver Fibrosis test, or clinical evidence of cirrhosis (e.g., liver nodularity and/or splenomegaly on imaging, platelet count $<150,000 / \mathrm{mm}^{3}$, etc.). Accordingly treatment is to be considered for patients of $\mathrm{CHC}$ with or without cirrhosis. Even recent EASL guidelines states that noninvasive methods should be used in patients with $\mathrm{CHC}$ instead of liver biopsy to assess liver disease severity prior to therapy as duration of treatment depends on presence or absence of cirrhosis (24).

VCTE is one of the most reliable methods for the assessment of liver fibrosis in CHC, but because of its high cost, its use is not widespread in low- and middleincome countries (27). In contrary, APRI and FIB-4 scores are two of the most popular scoring systems for liver fibrosis and have been reported to achieve high accuracy for the diagnosis of advanced fibrosis and cirrhosis in $\mathrm{CHC}$ patients compared to liver biopsy $(10,28)$. Though few studies have shown reduction in Liver Stiffness Measurement (LSM) using VCTE, along with other non-invasive fibrosis parameters like FIB-4 and APRI scores post DAA therapy in CHC, data remains scarce with other scores - Bonacini CDS, GUCI and Lok index (29-31).

Previous studies have revealed that APRI score with a cut-off value of 1 has a sensitivity, specificity, PPV, NPV of $61 \%, 64 \%, 81 \%$ and $40 \%$ respectively in determining F3-F4 fibrosis ; whereas, with a score of 2 , the values are $46 \%, 91 \%, 63 \%$ and $82 \%$ respectively (10). In our study, pre-treatment APRI score, with a cut-off value of 0.855 and post-treatment cut-off value of 0.63 was found to have better sensitivity, specificity and accuracy. Similarly, for FIB-4 score a cut-off value of $<1.45$ had a sensitivity, specificity and NPV of $74.3 \%, 80.1 \%$ and $94.7 \%$ and score $>3.25$ had sensitivity, specificity and PPV of $37.6 \%, 98.2 \%$ and $82.1 \%$ respectively for determining F3-F4 fibrosis (32). In our study, pretreatment FIB-4 score, with a cut-off value of 2.13 and post-treatment cut-off value of 1.64 was found to have better values. VCTE has a sensitivity, specificity, PPV, NPV of $67 \%, 89 \%, 48 \%$ and $95 \%$ at a cut-off value of 7.1 for $\mathrm{F} \geq 2 ; 73 \%, 91 \%, 81 \%$ and $87 \%$ at a cut-off value of 9.5 for $\mathrm{F} \geq 3$; and $87 \%, 91 \%, 95 \%$ and $77 \%$ respectively at a cut-off value of 12.5 for F4 (18).

Giannini et al in their prospective follow up study of $\mathrm{HCV}$ induced advanced, compensated liver disease after SVR to antivirals for a median duration of 60 weeks, has found that there is significant decrease in liver stiffness by VCTE, with progressive decline in APRI and FIB-4 score, spleen bi-polar diameter along with increase in platelet count, thus concluding that post SVR, there occurs improvement in liver stiffness, which is accompanied by an amelioration of indirect indices of liver fibrosis and function, and by a decrease in parameters of portal hypertension (33). This is concordant to our study, where we found a significant decline in liver stiffness measured by VCTE from $14.08 \pm 9.05 \mathrm{KPa}$ to $11.84 \pm 8.31 \mathrm{KPa}$ $(p=0.002)$ in post-treatment follow up of only 12 weeks. The platelet count has also increased from mean $( \pm \mathrm{SD})$ value of $181.64 \pm 72.4\left(\times 10^{9} / \mathrm{L}\right)$ to $199.56 \pm 77.96(\times$ $\left.10^{9} / \mathrm{L}\right)$, so is serum albumin from mean $( \pm \mathrm{SD})$ value of $3.7 \pm 0.47 \mathrm{~g} / \mathrm{dL}$ to $4.01 \pm 0.28 \mathrm{~g} / \mathrm{dL}$. There is significant decline in APRI score from $1.42 \pm 1.13$ to $0.54 \pm 0.35$ 
$(\mathrm{p}=0.003)$ and FIB-4 score from $2.88 \pm 3.02$ to $1.91 \pm$ $1.59(\mathrm{p}=0.027)$ as well.

Hsu et al in their retrospective analysis has shown that there is rapid and sustained reduction in non-invasive fibrosis indices- APRI and FIB-4 from week 2 until 12 weeks post treatment in patients with $\mathrm{CHC}$ who achieved SVR to DAA therapy (30). There was significant reduction in aminotransferase levels as well as increase in platelet count in post treatment period. However, unlike our study, LSM was measured using Acoustic Radiation Force Impulse (ARFI) elastography and the median LSM decreased from $1.78(1.25-2.30) \mathrm{m} / \mathrm{s}$ at baseline to 1.38 $(1.14-1.88) \mathrm{m} / \mathrm{s}$ at 12 weeks post-treatment $(\mathrm{P}<0.001)$. Similar finding was noted by Bachofner et al. in their observational study, where they found that median FIB4 and APRI values significantly decreased from 2.54 (IQR 1.65-4.43) and 1.10 (IQR 0.65-2.43) to 1.80 (IQR $1.23-2.84, \mathrm{p}<0.001$ ) and 0.43 (IQR 0.3-0.79, $<<0.001$ ), respectively (31). LSM using VCTE showed a regression of $32.41 \%$ after DAA treatment. The median VCTE prior to DAA treatment was $12.65 \mathrm{kPa}$ (IQR 9.45-19.2 $\mathrm{kPa}$ ) and decreased to $8.55 \mathrm{kPa}$ (IQR 5.93-15.25) posttreatment.

In the present study, GUCI at a cut-off value of 0.78 , had sensitivity, specificity and accuracy $88 \%, 80 \%$ and $84 \%$ with an AUC of 0.87 , for diagnosis of F3/F4 fibrosis in the pre-treatment period, whereas cut-off value of 0.64 had sensitivity $85 \%$, specificity $96 \%$ and accuracy $92 \%$, with an AUC of 0.97 in post-treatment period. Cordie et al has shown that GUCI at cut off $\geq$ 0.57 , is good indicator of significant fibrosis with $72 \%$ sensitivity, $66 \%$ specificity, and a PPV and NPV of $51 \%$ and $83 \%$, respectively (34). Although, Fouad et al has recommended a higher cut off of GUCI score of $\geq 1.56$ as an optimal cutoff value for the diagnosis of cirrhosis (35). Another study stated that under the cut off value of 0.33 , severe fibrosis and cirrhosis are not present (13).

Till date, no study has compared the evolution of GUCI in various time frame in relation to DAA therapy for chronic liver disease due to HCV. This study has shown that there is significant decrease in GUCI score in patients of CHC post DAA therapy.

Though post-DAA therapy, there is reduction in mean ( \pm SD) APRI, FIB-4 and GUCI scores in our patient cohort, but there was increase in mean Bonacini CDS and Lok index. Moreover, the cut-off value of predicting advanced fibrosis/cirrhosis (F3/F4) was found to be lower in post-treatment period for APRI, FIB-4 and GUCI score, this was not the case with CDS and Lok index. Previous studies have compared pre-treatment and post-treatment change in fibrosis scores using noninvasive parameters like VCTE, ARFI, and serum based markers- APRI and FIB-4 (29-31).

Lok et al from their HALT-C cohort has devised the model - Lok index, for which two cut points were introduced : 0.2 to rule out cirrhosis and 0.5 to confirm cirrhosis and the reported AUROC to detect cirrhosis was found to be $0.78-0.81$ (14). Masuzaki et al reported that Lok index and APRI correlated with histological fibrosis stages ( $\mathrm{rho}=0.581$, and 0.460 , respectively) and reported an AUROC (95\% CI) of 0.787 (0.741-0.832) and 0.692(0.639-0.745), respectively (15).

In our study, in pre-treatment period, Lok index at cutoff value of 0.41 was found to have similar sensitivity, specificity and accuracy of $80 \%$ for F3/F4 fibrosis, with an AUROC of 0.832 . However, in post-treatment period, unlike other non-invasive fibrosis markers the mean $( \pm \mathrm{SD})$ value of Lok index was paradoxically seen to increase. The cut-off value for significant fibrosis (F3/F4) in post-treatment period, was 0.525 , which had sensitivity, specificity and accuracy of $85 \%, 73.33 \%$ and $78 \%$ with an AUROC of 0.847.

Similarly, the mean $( \pm \mathrm{SD})$ value of Bonacini CDS was also found to increase in post-treatment period.

Four patients, who were exposed to Interferon based regimen and failed to achieve SVR, was included in our cohort and all of them achieved SVR 12 post DAA treatment.

After completion of treatment, the identification of advanced fibrosis and cirrhosis has important prognostic implication. Advanced liver fibrosis and cirrhosis are linked to worse liver-related outcomes in patients with CHC (36). Simmons et al in their long-term follow up study with 642 patients have found that the 5-year risk of $\mathrm{HCC}$ in patients with cirrhosis is $22.6 \%$, compared to only $3.2 \%$ in those without cirrhosis (37). The number of patients in our study who had advanced fibrosis $(\geq F 3)$ on VCTE, in the post treatment period was 69 (44.52\%). AGA guidelines also suggest following up such patients in dedicated hepatology center post-treatment (16). Although none of the patients had HCC in the follow up period. However, long term follow up of these patients is needed to confirm our findings.

Achieving SVR is known to reduce the risk of portal hypertension and its associated complications $(38,39)$. In our study, SVR 12 was present in $99.3 \%$ of our patients. Though fibrosis regression after SVR is variable and not ubiquitous, post-SVR reversal of cirrhosis is associated with an absence of liver-related complications (40). In our study, $5(3.2 \%)$ patients had post treatment worsening of liver function after achieving SVR. Two patients had ascites post treatment, with new onset of jaundice was seen in one patient. Two patients presented with variceal bleeding followed by further decompensating feature in form of ascites and encephalopathy.

In our study, in the pre-treatment period, FIB-4 score was found to perform better compared to other indices with a better specificity, accuracy and AUC value, however in the post-treatment period APRI and GUCI were better predictors of advanced fibrosis compared to FIB-4. Concurrent to our study, Papadopoulas et al in their retrospective comparison of VCTE with APRI and FIB-4 score in patients with $\mathrm{CHC}$ in pre-treatment period, found FIB-4 score to perform better than APRI score (41). Similarly, Verlinden et al in their Belgian cohort also found FIB-4 to perform better with better 
AUROC compared to APRI to discriminate between F0F2 and F3-F4 in CHC patients (42).

There are few limitations to our study. The most important being liver biopsy was not performed for assessment of fibrosis. The study being a single center one, the sample size was small. Although the study being a retrospective one, careful selection of patients were considered with strict inclusion criteria. We believe that a significant proportion of our study population (49\%) had F4 fibrosis in the pre-treatment period, despite including consecutive patients of $\mathrm{CHC}$ presenting to our centre. There is a possibility that it might distort the mean values of various indices, but it is unlikely to do so when population of different fibrosis stages are compared separately. Regarding the cutoff values we propose, they could be considered in patients of $\mathrm{CHC}$ for identifying advanced fibrosis/cirrhosis (F3/F4) both before and after therapy. There is a considerable difference in cut-off values of fibrosis scores in the pre-treatment and post-treatment period, which is supposedly due to improvement in hepatic inflammation post-DAA therapy. However, a reduction in fibrosis is also hypothesized, but in such a small follow-up duration, this might be less contributory for the same. Prospective study with pretratment and post-treatment liver biopsy might solve the query. In conclusion, our study demonstrated that in the pre-treatment period, the FIB-4 score with cutoff threshold of 2.13 and APRI score with cutoff threshold of 0.63 in the post-treatment period could potentially be used to predict patients with significant fibrosis. We believe that these markers could reduce the need for LSM by VCTE significantly, in pre-treatment evaluation of patients with $\mathrm{CHC}$, which would in turn allow a more rapid treatment decision for patients with $\mathrm{CHC}$, which is of special significance in the era of a worldwide HCV elimination plan. Moreover, in the post treatment period, patients requiring to attend surveillance program for HCC can be decided accordingly in absence of VCTE. However, larger prospective multi-center studies are needed to confirm our findings.

\section{Author's contribution}

P.D. the concept, design of the study and drafted the manuscript; S.N., P.J., S.C. data acquisition; A.S. statistical analysis; S.J. analyzed the data ; P.R., Q.C. critical revision for intellectual content. All authors critically revised the manuscript, approved the final version to be published, and agree to be accountable for all aspects of the work.

\section{Conflict of interest statement for each author}

None to disclose

\section{No financial support}

\section{References}

1. SHEPARD C.W., FINELLI L., ALTER M.J. Global epidemiology of hepatitis C virus infection. Lancet Infect. Dis., 2005, 5 : 558-67.

2. WHO. Global hepatitis report, 2017. April, 2017. https://www.who.int/ hepatitis/publications/global-hepatitis-report2017/en.

3. HOLMES J.A., CHUNG R.T. Hepatitis C. In : Feldman M, Friedman L, Brandt L, eds. Sleisenger and Fordtran's gastrointestinal and liver disease, 10th edn. Philadelphia : Saunders, 2016.

4. VAN DER MEER A.J., VELDT B.J., FELD J.J., WEDEMEYER H., DUFOUR J.F., LAMMERT F., et al. Association between sustained virological response and all-cause mortality among patients with chronic hepatitis $\mathrm{C}$ and advanced hepatic fibrosis. JAMA, 2012, $308: 2584-93$.

5. JANJUA N.Z., CHONG M., KUO M., WOODS R., WONG J., YOSHIDA E.M., et al. Long-term effect of sustained virological response on hepatocellular carcinoma in patients with hepatitis C in Canada. J. Hepatol., 2017, $66: 504-13$

6. WHO. Combating hepatitis B and C to reach elimination by 2030. May, 2016. https://www.who.int/hepatitis/publications/hep-eliminationby-2030-brief/ en/.

7. FRIEDRICH-RUST M., ONG M.F., MARTENS S., SARRAZIN C., BOJUNGA J., ZEUZEM S., et al. Performance of transient elastography for the staging of liver fibrosis : a meta-analysis. Gastroenterology, 2008, 134(4) : 960-74.

8. DEGOS F., PEREZ P., ROCHE B., MAHMOUdi A., ASSELINEAU J., VOITOT H., et al. Diagnostic accuracy of FibroScan and comparison to liver fibrosis biomarkers in chronic viral hepatitis : a multicenter prospective study (the FIBROSTIC study). J. Hepatol., 2010, 53(6) : 1013-21

9. CASTERA L., LIK YUEN CHAN H., ARRESE M. EASL-ALEH Clinical Practice Guidelines : noninvasive tests for evaluation of liver disease severity and prognosis European Association for the Study of the Liver. J. Hepatol., $2015,63: 237-264$

10. LIN Z.H., XIN Y.N., DONG Q.J., WANG Q., JIANG X.J., ZHAN S.H., et al. Performance of the aspartate aminotransferase-to-platelet ratio index for the staging of hepatitis C-related fibrosis : an updated meta-analysis. Hepatology, 2011, 53 : 726-736.

11. STERLING R., LISSEN E., CLUMECK N., SOLA R., CORREA M.C., MONTANER J., et al. APRICOT Clinical Investigators. Development of a simple noninvasive index to predict significant fibrosis patients with HIV/ HCV co-infection. Hepatology 2006, 43 : 1317-1325.

12. COlli A., COlUCCI A., PAGGI S., FRAQUElli M., MASSIRONI S., ANDREOLETTI M., et al. Accuracy of a predictive model for severe hepatic fibrosis or cirrhosis in chronic hepatitis C. World J Gastroenterol 2005, 11(46) :7318-22.

13. WESTIN J., YDREBORG M., ISLAM S., ALSIÖ Å., DHILLON A.P., PAWLOTSKY J.M., et al. A noninvasive fibrosis score predicts treatment outcome in chronic hepatitis C virus infection. Scand. J. Gastroenterol., 2008, 43(1) : $73-80$.

14. LOK A.S., GHANY M.G., GOODMAN Z.D., WRIGHT E.C., EVERSON G.T., STERLING R.K., et al. Predicting cirrhosis in patients with hepatitis C based on standard laboratory tests : results of the HALT-C cohort. Hepatology, 2005, $42:$ 282-92.

15. MASUZAKI R., TATEISHI R., YOSHIDA H., GOTO E., SATO T., OHKI T., et al. Prospective Comparison of Liver Stiffness Measurement and Lok Index in Chronic Hepatitis C Patients. Gastroenterology, 2008, 134(4) Supplement 1 : Page A-795.).

16. LIM J.K., FLAMM S.L., SINGH S., FALCK-YTTER Y.T., GERSON L., HIRANO I., et al. American Gastroenterological Association Institute guideline on the role of elastography in the evaluation of liver fibrosis. Gastroenterology, 2017 May 1, 152(6) : 1536-43.

17. CASTERA L. Noninvasive methods to assess liver disease in patients with hepatitis B or C. Gastroenterology, 2012, 142(6) : 1293-302 e4.

18. CASTÉRA L., VERGNIOL J., FOUCHER J., LE BAIL B., CHANTELOUP E., HAASER M., et al. Prospective comparison of transient elastography, Fibrotest, APRI, and liver biopsy for the assessment of fibrosis in chronic hepatitis C. Gastroenterology 2005, $128: 343-350$.

19. ZIOL M., HANDRA-LUCA A., KETTANEH A., CHRISTIDIS C., MAL F., KAZEMI F., et al. Noninvasive assessment of liver fibrosis by measurement of stiffness in patients with chronic hepatitis C. Hepatology, 2005, 41 : 48-54.

20. SANDRIN L., FOURQUET B., HASQUENOPH J.M., YON S., FOURNIER C., MAL F., et al. Transient elastography : a new noninvasive method for assessment of hepatic fibrosis. Ultrasound Med. Biol., 2003, 29 : 1705-1713.

21. BONACINI M., HADI G., GOVINDARAJAN S., LINDSAY K.L. Utility of a discriminant score for diagnosing advanced fibrosis or cirrhosis in patients with chronic hepatitis C virus infection. Am. J. Gastroenterol., 1997, 92 : 1302-4. 
22. WAI C.T., GREENSON J.K., FONTANA R.J., KALBFLEISCH J.D., MARRERO J.A., CONJEEVARAM H.S., et al. A simple noninvasive index can predict both significant fibrosis and cirrhosis in patients with chronic hepatitis C. Hepatology, 2003, 38 : 518-526.

23. KANDEMIR O., POLAT G., SARAÇOĞLU G., TAȘDELEN B. The predictive role of AST level, prothrombin time, and platelet count in the detection of liver fibrosis in patients with chronic hepatitis C. Turk. J. Med. Sci, 2009, 39 (6) : 857-862.

24. European Association for the Study of the Liver. EASL Recommendations on Treatment of Hepatitis C 2018. J. Hepatol., (2018), https://doi.org/10.1016/ jhep.2018.03.026.

25. MUYLDERMANS G., BIELEN R., BOTTERMAN R., BOURGEOIS S., COLLE I., DERESSA B., et al. Hepatitis C virus (HCV) prevalence estimation in the adult general population in Belgium : a meta-analysis. Acta Gastroenterol. Belg., 2019, 82(4) : 479-485.

26. GHANY M.G., MORGAN T.R. Hepatitis C Guidance 2019 Update: American Association for the Study of Liver Diseases-Infectious Diseases Society of America Recommendations for Testing, Managing, and Treating Hepatitis C Virus Infection. Hepatology (Baltimore, Md.), 2020 Feb 1, 71(2) : 686-721.

27. AFDHAL N.H., BACON B.R., PATEL K., LAWITZ E.J., GORDON S.C., NELSON D.R.., et al. Accuracy of Fibroscan, compared with histology, in analysis of liver fibrosis in patients with hepatitis B or C : a United States multicenter study. Clin. Gastroenterol. Hepatol., 2015, 13 : 772-779.e1-e3.

28. KIM B.K., KIM D.Y., PARK J.Y., AHN S.H., CHON C.Y., KIM J.K., et al. Validation of FIB-4 and comparison with other simple noninvasive indices for predicting liver fibrosis and cirrhosis in hepatitis B virus-infected patients. Liver Int., 2010, 30 : 546-553.

29. DOLMAZASHVILI E., ABUTIDZE A., CHKHARTISHVILI N., KARCHAVA M., SHARVADZE L., TSERTSVADZE T. Regression of liver fibrosis over a 24-week period after completing direct-acting antiviral therapy in patients with chronic hepatitis $\mathrm{C}$ receiving care within the national hepatitis $\mathrm{C}$ elimination program in Georgia: results of hepatology clinic HEPA experience. European journal of gastroenterology \& hepatology, 2017 Nov 1, 29(11) : 1223-30

30. HSU W.F., LAI H.C., SU W.P., LIN C.H., CHUANG P.H., CHEN S.H., et al. Rapid decline of noninvasive fibrosis index values in patients with hepatitis $\mathrm{C}$ receiving treatment with direct-acting antiviral agents. $B M C$ gastroenterology, 2019 Dec, 19(1) : 63.

31. BACHOFNER J.A., VALLI P.V., KRÖGER A., BERGAMIN I., KÜNZLER P., BASERGA A., et al. Direct antiviral agent treatment of chronic hepatitis $\mathrm{C}$ results in rapid regression of transient elastography and fibrosis markers fibrosis - 4 score and aspartate aminotransferase - platelet ratio index. Liver International, 2017 Mar, 37(3) : 369-76.
32. VALLET-PICHARD A., MALLET V., NALPAS B., VERKARRE V., NALPAS A., DHALLUIN-VENIER V., et al. FIB-4 : an inexpensive and accurate marker of fibrosis in $\mathrm{HCV}$ infection. Comparison with liver biopsy and fibrotest. Hepatology, 2007, 46(1) : 32-36.

33. GIANNINI E.G., CRESPI M., DEMARZO M., BODINI G., FURNARI M., MARABOTTO E., et al. Improvement in hepatitis $\mathrm{C}$ virus patients with advanced, compensated liver disease after sustained virological response to direct acting antivirals. European journal of clinical investigation, $2019 \mathrm{Mar}$, 49(3) : e13056.

34. CORDIE A., SALAMA A., EL-SHARKAWY M., EL-NAHAAS S.M. KHAIRY M., ELSHARKAWY A., et al. Comparing the efficiency of Fib4, Egy-score, APRI, and GUCI in liver fibrosis staging in Egyptians with chronic hepatitis C. Journal of medical virology, 2018 Jun, 90(6) : 1106-11.

35. FOUAD S., ESMAT S., OMRAN D., KOBAISI M. Noninvasive assessment of hepatic fibrosis in Egyptian patients with chronic hepatitis $\mathrm{C}$ virus infection. World J. Gastroenterol., 2012, 18(23) : 2988-94.

36. CHARLTON M., EVERSON G.T., FLAMM S.L., KUMAR P., LANDIS C., BROWN JR. R.S., et al. Ledipasvir and sofosbuvir plus ribavirin for treatment of $\mathrm{HCV}$ infection in patients with advanced liver disease. Gastroenterology, 2015, 149(3) : 649-59.

37. SIMMONS B., SALEEM J., HEATH K., COOKE G.S., HILL A. Long-term treatment outcomes of patients infected with hepatitis $\mathrm{C}$ virus : a systematic review and meta-analysis of the survival benefit of achieving a sustained virological response. Clin. Infect. Dis., 2015, 61(5) : 730-40.

38. MANDORFER M., KOZBIAL K., SCHWABL P., FREISSMUTH C., SCHWARZER R., STERN R., et al. Sustained virologic response to interferon-free therapies ameliorates $\mathrm{HCV}$-induced portal hypertension. $J$. Hepatol., 2016, 65(4) : 692-9.

39. LENS S., ALVARADO-TAPIAS E., MARINO Z., LONDOÑO M.C., LLOP E., MARTINEZ J., et al. Effects of all-oral anti-viral therapy on HVPG and systemic hemodynamics in patients with hepatitis $\mathrm{C}$ virus-associated cirrhosis. Gastroenterology, 2017, 153(5) : 1273-1283.e1.

40. CARMONA I., CORDERO P., AMPUERO J., ROJAS A., ROMEROGOMEZ M. Role of assessing liver fibrosis in management of chronic hepatitis C virus infection. Clin. Microbiol. Infect., 2016, 22(10) : 839-45.

41. PAPADOPOULOS N., VASILEIADI S., PAPAVDI M., SVERONI E., ANTONAKAKI P., DELLAPORTA E., et al. Liver fibrosis staging with combination of APRI and FIB-4 scoring systems in chronic hepatitis C as an alternative to transient elastography. Annals of gastroenterology, $2019 \mathrm{Sep}$, 32(5) : 498-503.

42. VERLINDEN W., BOURGEOIS S., DE M.M., VONGHIA L., VANWOLLEGHEM T., MICHIELSEN P., et al. Validation of APRI and FIB-4 score in an Antwerp cohort of chronic hepatitis C patients. Acta gastroenterologica Belgica, 2015 Dec, 78(4) : 373-80. 